\title{
$\mathrm{SMS}$ 를 이용한 모바일 퀴즈 시스템
}

\author{
박효원 ${ }^{1}$, 이경득 ${ }^{1}$, 이순흠 ${ }^{*}$, 김선형 ${ }^{1}$ \\ ${ }^{1}$ 순천향대학교 정보통신공학과
}

\section{The Mobile Quiz System Using SMS}

\author{
Hyo-won Park ${ }^{1}$, Kyoung-Deug Lee ${ }^{1}$, Sunheum Lee ${ }^{1^{*}}$ and Sun-Hyung Kim ${ }^{1}$ \\ ${ }^{1}$ Dept. of Information and Communication Engineering, SoonChunHyang University
}

\begin{abstract}
요 약 본 논문에서는 교육현장에서 간편하게 활용할 수 있는 SMS를 이용한 모바일 퀴즈 시스템을 개발하였다. 본 시스템은 즉각적으로 학생들에게는 퀴즈 결과에 대한 SMS 개별통보를, 교수자에게는 성적 통계를 제공한다. 실 제 대학교육 현장에서의 시험운용을 통해, 본 시스템이, 학생들에게는 강의에 대한 흥미를 유발하고 몰입도를 높이 며 교수자에게는 강의 수준을 즉각적으로 적절히 조절할 수 있는 교육 수단을 제공하여, 효과적인 교육도구로 활용 될 수 있을 것으로 기대된다.
\end{abstract}

\begin{abstract}
In this paper, a mobile quiz system using SMS has been developed, which can be conveniently used on the spot of education. The system immediately not only provides each individual student with the results of his/her quizzes but also a instructor with the statistics of the results by SMS. Field tests of the quiz system have shown that it can be effectively used as a good teaching tool for teachers getting immediate feedback from participants in the lecture and adjusting teaching level as well as for inducing more interest in learning from participants and raising their concentration on the class.
\end{abstract}

Key Words : SMS(Short message service), Mobile education, Mobile quiz, GNEX, Mobile C

\section{1. 서론}

강의 현장에서 교수자는 학습자의 강의 내용 이해의 정도를 파악하여 강의 수준을 조절하기 위해 강의 중간 중간 질문을 하여 대답을 유도한다. 그러나 일반적으로 수강생들은 강의 내용을 잘 이해하지 못하고 있더라도 이를 잘 표현하지 않거나, 이해를 하고 있는 경우도 적극 적으로 응답하지 않는 관습적인 소극성으로 인해 교수자 는 강의의 수준을 조절하기 힘든 것이 현실이다. 따라서 타인을 의식하지 않아도 되는 익명성을 보장할 수 있는 응답 방법이 제시된다면 보다 적극적인 학습자의 응답을 유도할 수 있을 것이라 생각된다. 본 논문에서는 이러한 목적을 달성할 수 있는 방법으로 SMS를 이용한 모바일 퀴즈 시스템을 제안하였으며, 퀴즈 시스템 구현에 있어서
교수자와 수강생이 강의현장에서 간편하게 사용할 수 있 는 환경을 제공하는데 목표를 두었다.

$\mathrm{SMS}$ 를 교육 분야에 적용한 참고문헌[1]의 경우, 교육 자료를 단순히 SMS 메시지로 전달하는 가능만을 구현하 였으며, 참고문헌[2]의 경우, 관리기관이 교육운영관리의 효율성을 높이고, 교육기관 또는 교육생에게 고객 만족도 를 높이는 목적으로 SMS가 활용될 수 있음 보인 것으로 실시간 소통의 도구로써의 기능은 포함하고 있지 않다. 참고문헌[3]은 가입자의 기분이나 상황은 고려하지도 않 은 채 무작위적 방식으로 폭주하는 모바일 광고 $\mathrm{BM}$ 방식 의 문제점을 해결하기 위한 방식을 제안한 것으로 퀴즈 출제 및 응답을 통해 이를 해결하는 방식이 본 논문과 유 사하나, 교육 현장에서 효과적인 실시간 교육도구로 활용 될 수 있는지에 대한 본 논문 연구와는 관점을 달리하고

*교신저자 : 이순흠(sunheum@sch.ac.kr) 
있다. 본 논문의 SMS 이용은 수업 중 남을 의식하는 등 관습적으로 응답에 소극적인 우리의 교육 환경에서 학생 들이 적극적으로 수업에 참여할 수 있는 방법을 제공하 려는 동기로 시작되었다. 익명성이 제공되는 쪽지 시험을 통해 수업시간의 의사소통의 수준을 제고하여 수업의 참여도를 높이려는 시도도 번거롭고 시간이 많이 소요되 는 관계로 실시간성을 달성할 수 없다는 경험도 본 연구 를 시작하게 된 배경이다.

$\mathrm{SMS}$ 는 전송 가능한 데이터의 길이가 $80 \mathrm{Byte}$ (한글 40 자, 영어, 숫자 80자)로 제한되어 있으나, 사용자가 단말 기를 항상 휴대한다는 특징으로 E-Mail과 달리 사용자에 게 발송 시점과 거의 동시에 전달되는 즉시성과 사용의 편리성으로 인해 통신 수단의 하나로 이미 확고한 자리 를 굳힌 상태이며, 본 논문에서 구현하고자 하는 퀴즈 시 스템이 요구하는 익명성, 즉시성과 사용의 편리성을 모두 만족시키는 특징을 갖는다[4,5].

본 논문의 퀴즈 시스템은 Web기반의 LMS가 제공하 는 다양한 형태의 문제출제와 평가방법을 제공[5-9]하지 는 못하지만, 교수자가 강의 현장에서 구두, 판서, 시험 지 또는 빔프로젝터로 출제하는 퀴즈에 대한 응답을 수 강생이 즉각적으로 SMS 형태로 응답할 수 있게 한다. 그 리고 서버로 전송된 응답 SMS들은 처리되어 교수자에게 즉각적으로 전송되어, 교수자가 수강생의 정답률을 참고 로 강의의 수준과 완급을 조절할 수 있게 한다. 수강생의 경우, 학습 내용을 바로 현장에서 평가 받는 형식이므로 강의에 대한 몰입도가 높아지고, 개인별로 회신되는 퀴즈 성적은 학습 현장에서 보다 자발적으로 수업에 참여하게 할 것이다.

수강생에게 SMS 서비스 비용이 전가된다는 문제점도 있지만, 일반적으로 20 대 이하의 연령대의 SMS 소비 패 턴이 월 정액제를 사용하고 있어 큰 문제는 아니라고 생 각된다. WAP(Wireless Application Protocol)이나 일반 무 선인터넷을 이용하여 좀 더 고수준의 피드백이 이루어지 도록 할 수 있으나, 비용, 편리성, 즉시성 측면에서 SMS 에 뒤떨어진다.

본 시스템은 소극적이고 피동적인 학습현장에서 교수 자에게 강의의 수준을 효과적으로 조절할 수 있는 교육 도구를 제공할 목적으로 구현되었지만, 다양한 현장에서 즉각적인 결과를 알 수 있는 모바일 퀴즈 또는 설문 조 사 시스템으로도 활용될 수 있을 것이다. 2장에서는 본 시스템 구현 범위를 결정하기 위한 요구분석 내용을 기 술하였으며, 3장에서는 퀴즈 시스템의 설계, 구현, 시험 결과를 보이고, 4장에서 결론을 내렸다.

\section{2. 요구분석}

본 논문의 퀴즈 시스템은 Web기반의 LMS 등과 같이 다양하고 복잡한 기능을 제공하는 것을 목적으로 하는 것이 아니라, 교수자가 교육현장에서 최대한 손쉬운 방법 으로 강의 도중 학생들의 이해도를 파악하여 강의 수준 을 조절할 수 있게 함으로써 학생들의 강의 몰입도 및 참 여도를 증진시키는데 그 목적이 있으므로, 휴대폰의 $\mathrm{SMS}$ 를 이용하여 다음의 요구사항을 제공할 수 있도록 구현하였다.

교수자는 수업 중 구두나 판서 등으로 수업내용에 대 한 퀴즈문제나 기타 수업진행에 관련된 문제를 출제한다. SMS 1 회 전송 가능한 문자수가 80 바이트로 제한되므로, 출제되는 문제 형식은 $\mathrm{O} / \mathrm{X}$, 선다형, 단답형으로 제한되 고 1 회 출제될 수 있는 문제의 수도 $\mathrm{O} / \mathrm{X}$ 와 선다형으로만 구성된 경우 20 문제 이하로, 단답형 주관식인 경우 정답 의 길이에 따라 제한된다. 추후 성적처리 및 관리를 수월 하게 할 수 있도록, 교수자가 교수 ID, 시험문제지 ID, 시험문제 문항 수 그리고 정답으로 구성된 퀴즈시험 정 보를 수업현장에서 손쉽게 설정할 수 있도록 한다. 교수 자는 퀴즈 종료 즉시 학생들이 제출한 퀴즈결과에 대한 성적 통계를 SMS 메시지로 전달받는다. 수강생이 교수 자가 제공하는 교수 $\mathrm{ID}$, 시험문제지 $\mathrm{ID}$, 시험문제 문항수 를 설정한 후 각 문제에 대한 정답을 손쉽게 입력할 수 있는 기능이 제공된다. 수강생이 시험 답안을 전송한 후 제출된 답안의 정보는 수강생 휴대폰에 저장되도록 한다. 수강생 또한 답안 전송 후 즉시 개별적으로 시험 결과를 통보받게 한다. 이상에서 교수자와 학습자를 위한 각각의 클라이언트 프로그램이 제공해야하는 기능을 간단히 요 약했다.

본 논문의 SMS 퀴즈 시스템 서버 프로그램은 SMS 전 용모뎀을 제어하여 교수자와 수강생의 SMS 메시지들을 수신한 후, 기 설정된 교수자와 수강생의 DB 정보를 기 초로 하여 수신된 SMS 메시지를 처리한다. 처리된 성적 정보는 서버 $\mathrm{DB}$ 에 저장되는 동시에 개인별로 $\mathrm{SMS}$ 메시 지로 통보되며 성적 통계 정보는 교수자에게 통보된다. 또한 서버 프로그램은 교수자나 수강생이 추후 웹 페이 지를 통해 상세한 퀴즈 결과 및 통계에 접근할 수 있는 통로를 제공한다. 인터넷 환경과 노트북이 활용되는 수업 환경이면 교수자는 웹을 통해 수강생 개인별 퀴즈 성적 등과 같은 보다 세부적인 정보를 수업에 활용할 수도 있 다. 


\section{3. 설계 및 구현}

\section{1 시스템의 구성 및 기능}

본 논문에서 구현한 퀴즈 시스템의 구성도는 그림 1 과 같다. 여기서 관리자는 교수자 또는 시스템 관리자를 의미하여 사용자는 수강생을 의미한다. 교수자는 퀴즈시 험 정보를 휴대폰 단말기를 통해 수업현장에서 설정하거 나 사전에 $\mathrm{PC}$ 의 웹페이지 인터페이스를 통해 설정할 수 있다. 수강생은 자신의 휴대폰에 설치된 본 논문의 클라 이언트 프로그램을 사용하여 퀴즈 시험에 응시하며 SMS 로 시험 결과를 즉시 통보받는다. 수업 후 웹을 통해 수 강 기간 동안 축적된 퀴즈 시험 문제들 및 결과들을 조 회할 수 있다. 퀴즈 서버는 SMS 전용모뎀을 제어하여 대 량의 SMS 메시지 수신시 버퍼 오버풀로우나 중복수신 문제가 발생하지 않도록 한다. 수신된 SMS 메시지가 교 수자로부터 온 것인지 수강생으로부터 온 것인지를 구분 한 후, 교수 ID, 시험문제지 ID, 시험문제 문항수 정보를 이용하여 시험정보를 설정하거나 채점을 수행한다. 처리 가 완료되면 교수자와 수강생들에게 결과를 즉시 통보한 다.

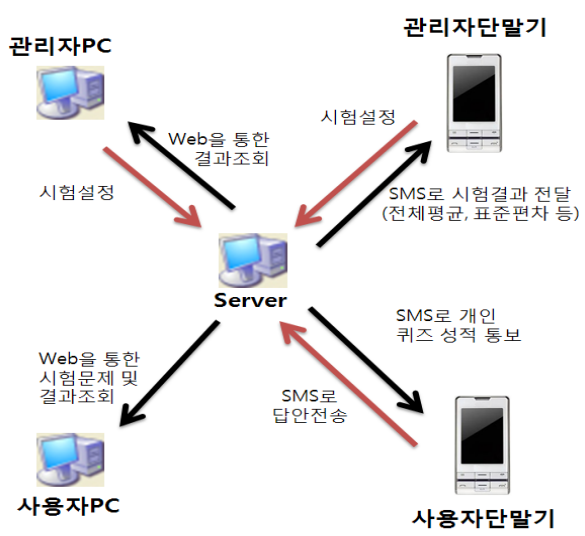

[그림 1] 전체 시스템 구성도

\section{2 구 현}

본 논문의 교수자와 학습자용 클라이언트 프로그램은 신지소프트의 모바일 플랫폼인 Mobile-C 기반의 GNEX 위에 구현되었다. 서버 측에서 SMS 모뎀의 제어와 메시 지 처리 및 관리를 위해 $\mathrm{C \#}$ 을 사용하였고, $\mathrm{DB}$ 와 웹페이 지 연동을 위해 PHP와 HTML을 이용하였다.

교수자용 클라이언트 프로그램은 교수 $\mathrm{ID}$, 시험문제지 $\mathrm{ID}$, 시험문제 문항 수 그리고 정답으로 구성된 퀴즈시험 정보를 설정하는 기능을 제공한다. 수강생용 클라이언트
프로그램은 정답 설정 부분을 제외한 교수자용 클라이언 트 프로그램을 포함하여 그림 2 와 같은 기능을 제공한다.

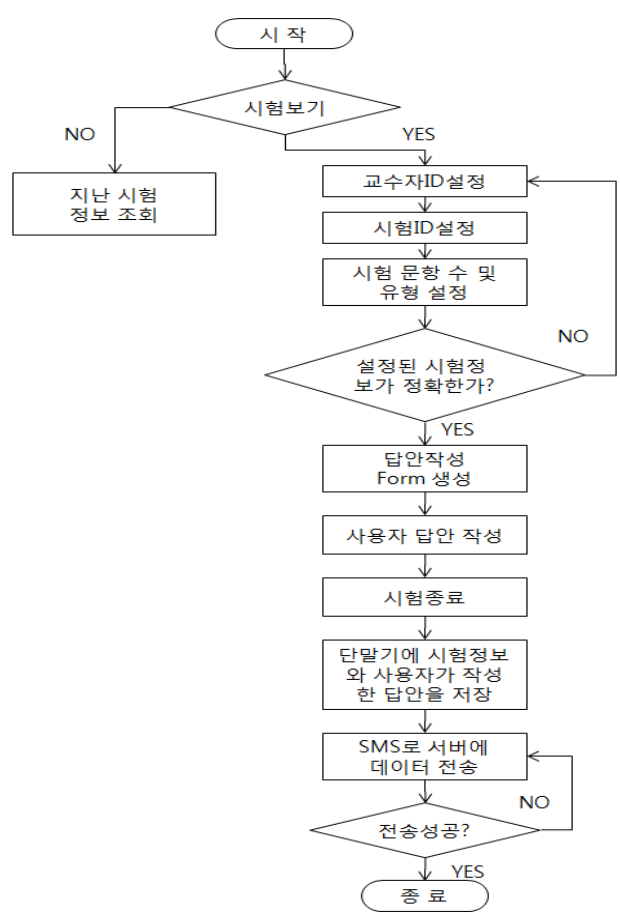

[그림 2] 수강생용 프로그램 흐름도

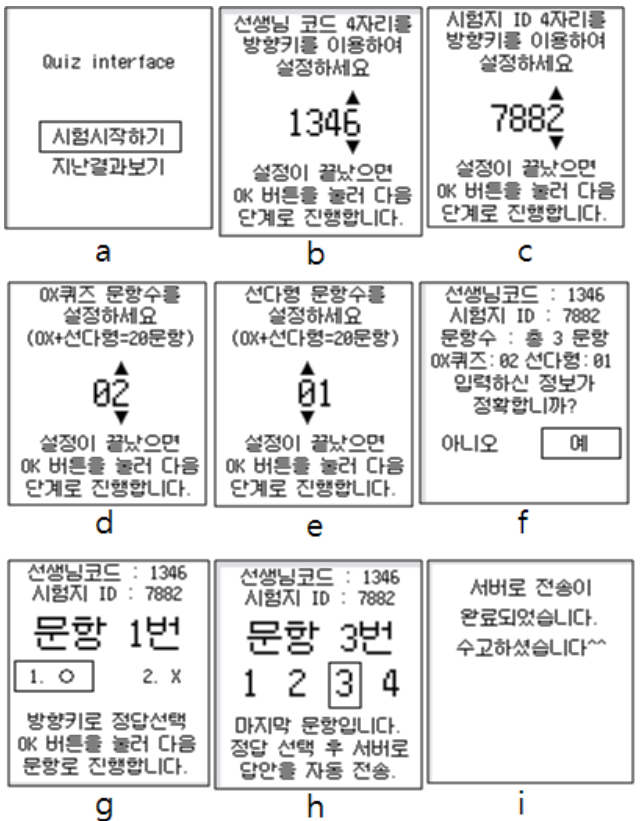

[그림 3] 시험정보 설정 및 답안 작성 화면 


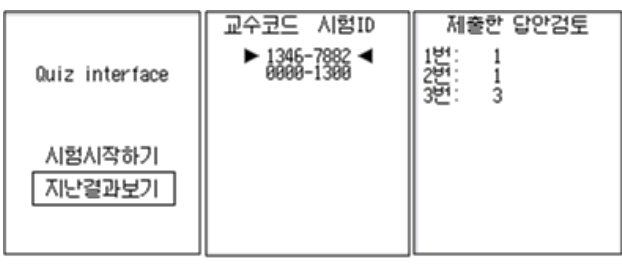

[그림 4] 과거에 전송한 데이터의 조회

그림 3과 4는 프로그램 실행 단계별로 보이는 수강생 휴대폰 화면 영상을 캡춰한 것이다. 그림 $3 \mathrm{a}$ 는 시작메뉴 이고, 그림 $3 \mathrm{~b}$ 는 교수자 $\mathrm{ID}$ 를 설정하는 화면이다. 교수자 $\mathrm{ID}$ 는 사전에 선생님 별로 배정되는 4 자리 숫자이다. 그림 $3 \mathrm{c}$ 는 시험 문제지 관리를 위한 시험지 $\mathrm{ID}$ 를 설정하는 화 면이다. 이 ID는 교수자가 생성하여 관리하는 4자리 숫자 이다. 중복 설정은 할 수 없도록 프로그램에서 처리하고 있다. 그림 $3 \mathrm{~d}$ 는 $\mathrm{O} / \mathrm{X}$ 문항 수를 설정하고 그림 $3 \mathrm{e}$ 는 선다 형 문항 수를 설정하는 화면이다. $\mathrm{O} / \mathrm{X}$ 형 2 문제와 선다 형 1 문제가 출제된 것이다.

단답형 문항이 없을 경우, 두 형식의 문항 수의 합이 20 문제 이하로 설정되도록 제한된다. 모든 설정은 방향 키를 이용하여 손쉽게 설정할 수 있다. 그림 $3 \mathrm{f}$ 는 입력된 퀴즈시험 정보가 정확한 지 확인하는 단계이다. 그림 $3 \mathrm{~g}$ 와 $3 \mathrm{~h}$ 는 답을 입력하는 화면이다. 출제된 순서대로 답안 입력 화면이 제공된다. 2 번 문제에 대한 답안 입력 화면 은 지면관계상 생략하였다. 정해진 문항 수의 답안의 입 력이 완료되면 자동으로 휴대폰에 시험정보와 답안을 파 일로 저장하는 동시에 SMS 메시지로 서버로 전송한다. 송신 데이터 포맷은 ‘@\#\$교수코드\#시험코드\#문항수\#정 답'의 형태로 이루어진 하나의 문자열을 사용한다. 현재 시스템에서 설정된 교수 측 프로그램의 데이터 헤더는 ‘!@@’, 학생 측 $\mathrm{SMS}$ 의 데이터 헤더는 '!@\#’로 설정 되어 있다. 예를 들어 '!@\# $\$ 1346 \#$ 7882\#03\#332' 라는 SMS 데이터는 학생 사용자가 서버로 교수 코드 1346, 시 험지 코드 7882 의 3 문제짜리 시험을 응시하였고 그 정답 을 1 번에 3 번, 2 번에 3 번, 3 번에 2 번을 입력하여 서버로 전송했음을 의미한다. 전송이 완료되면 그림 $3 \mathrm{i}$ 와 같이 화면이 출력된다. 수강생은 제출된 답안들을 추후 그림 4 와 같이 휴대폰에서 열람할 수 있다.

이상에서 설명된 송신데이터 포맷의 문자열을 생성하 는 MakeSMSdata 함수를 구현한 코드의 일부를 그림 5에 보였다. $\quad$ t1 t4까지가 선생님코드를 저장하는 변수이고 qn1, qn2가 문항수를 저장하는 변수, qid1 qin4까지가 시 험지 $\mathrm{ID}$ 를 저장하는 변수이다. 이렇게 각 자리수별로 저 장된 변수들과 앞에서 설명한 구분기호들을 문자 삽입을 위한 시스템 함수인 PutChar를 이용하여 최종 전송 데이
터 저장 변수인 final_sms_data에 삽입한다. 그리고 MakeSMSdata 함수 하단에 있는 for문에서 동적으로 생 성된 문항 수만큼 문제의 답안들을 삽입하는 것으로 서 버로 전송할 최종 SMS데이터를 생성한다. Mobile-C에서 제공하는 API에는 프로그램 코드의 길이를 줄일 수 있는 다양한 문자열 처리 함수들이 다수 존재한다. 그러나 PC 개발 환경하의 에뮬레이터에서는 아무런 문제가 없지만, 실제 핸드폰에서 프로그램을 테스트 하였을 때 데이터 생성 단계에서 데이터가 소실되거나 프로그램이 정상동 작하지 않은 관계로 PutChar 함수를 사용하였다.

\section{void MakeSMSdata()}

$\{$ teacher_code_int=AsciiToInt(teacher_code); quiz_id_int=AsciiToInt(quiz_id); $\mathrm{t} 4=$ teacher_code_int $/ 1000+48$;

$\mathrm{t} 3=(($ teacher_code_int\%1000)-(teacher_code_int\%100) $)$ $/ 100+48$;

$\mathrm{t} 2=($ teacher_code_int $\% 100$-teacher_code_int $\% 10) / 10+4$ 8 ;

$\mathrm{t} 1=$ teacher_code_int $\% 10+48$;

qn2 $=($ quiz_num-1 $) / 10+48$;

qn1 $=($ quiz_num -1$) \% 10+48$;

qid4=quiz_id_int $/ 1000+48$;

qid3=((quiz_id_int\%1000)-(quiz_id_int\%100) $) / 100+48$; qid2=(quiz_id_int\%100-quiz_id_int\%10)/10+48; qid $1=$ quiz_id_int $\% 10+48$;

PutChar(final_sms_data, 0, '!');

PutChar(final_sms_data, 1, '@');

$<$ 생략>

PutChar(final_sms_data, 15, qn2);

PutChar(final_sms_data, 16, qn1);

PutChar(final_sms_data, 17, '\#');

for(array_index $=0$; array_index $<$ quiz_num- 1 ; array_inde $\mathrm{x}++)$

$\{\mathrm{mp}=$ array_index +18 ;

PutChar(final_sms_data,tmp,answer_array[array_ index]);

\}

PutChar(final_sms_data, tmp $\left.+1,{ }^{\prime} \backslash 0^{\prime}\right)$; \}

[그림 5] 단말기에서 SMS 데이터 생성을 위한 함수 
송신할 SMS 문자열의 생성이 완료되면 그림6의 sentToServer 함수에 의해 서버로 전송된다. SendSMS 함 수는 SMS 발신을 위해 제공되는 시스템 함수이며, 매개 변수는 SMS Server 에게 전송하는 통신사 고유번호, 수 신번호, 발신할 문자열로 구성된다.

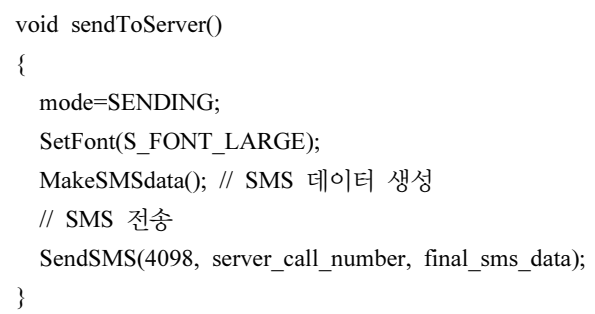

[그림 6] 단말기에서 SMS 전송을 위한 함수

서버는 그림 7과 같은 절차를 통해 수신된 SMS 메시 지들을 처리한다.

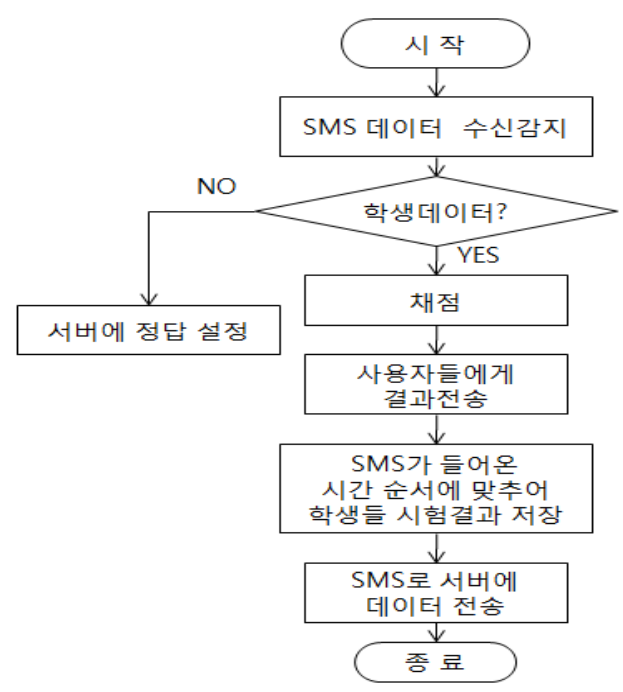

[그림 7] 서버의 동작 흐름

교수자와 수강생은 퀴즈시험 종료와 동시에 서버로부 터 SMS 메시지로 시험 결과와 성적통계를 각각 받게 된 다.

그림 8에 수강생의 휴대폰 전화번호로 구분되며 수신 시간 순서로 서버에 저장된 시험정보, 제출된 답안 및 정 답을 보여주는 교수용 web페이지를 보였다.

\begin{tabular}{|c|c|c|c|c|c|}
\hline 시간 & 전화번호 & 교수 퀴즈 문항 & 답 & 점수 & 채점 \\
\hline 20090923153424 & 0106880 & 000100015 & 11333 & 2 & $x \times 00 x$ \\
\hline 20090923153435 & 0104184 & 000100015 & 14334 & & xooox \\
\hline 20090923153438 & 0104645 & 000100015 & 44333 & 4 & $0000 x$ \\
\hline \multicolumn{6}{|c|}{ 생 략 } \\
\hline 20090923173215 & 0105214 & 000100015 & 43334 & 3 & $0 \times 00 x$ \\
\hline 20090923173223 & 0109044 & 000100015 & 43333 & 3 & $0 x 00 x$ \\
\hline 20090923173306 & 0103663 & 000100015 & 11122 & 1 & $X X X X O$ \\
\hline 20090923173924 & 0106253 & 000100015 & 11111 & 0 & $x X X X X$ \\
\hline
\end{tabular}

[그림 8] 결과 조회 웹페이지

\section{3 테스트 및 설문조사}

본 논문에서 구현한 시스템을 학생 38 명의 클래스에 서 테스트하였다. 20 분 수업 후, 수업 내용을 묻는 5 7문 제의 퀴즈를 본 논문의 프로그램으로 실시하였다. 문제 들 중에 정답률이 $60 \%$ 이하인 문제에 대해서는 관련 강 의 내용을 다시 설명하였다. 이후 표 1 과 같은 내용의 설 문지를 사용하여 설문조사를 시행하였다. '매우 그렇다', '그렇다', '잘 모르겠다', '아니다', '매우 아니다'의 5 단 계 응답지를 사용하였다. 설문 조사 결과는 표 2 와 같다.

6개 설문 문항 모두에 대해 '매우 그렇다'와 '그렇다 '에 응답한 학생이 $70 \%$ 이상인 결과는 본 프로그램에 대 해 학생들이 대체적으로 긍정적으로 받아들이고 있음을 의미한다. 또한 학생들이 본 논문의 시스템의 어떤 특징 이 학습도구로서 효용성을 높이는지에 대한 질문에 대해 익명성을제일 요인으로 응답하였다.

본 실험의 결과는 교수자가 출제하는 퀴즈 문제의 난 이도와 퀴즈 문제의 정답률의 활용 기준, 교수법, 학생의 수업능력 및 수업태도 등 기타 여러 가지 변수들에 의해 가변적일 수 있을 것으로 사료되나, 본 테스트를 통해 본 프로그램이 수업 중에 교수자와 수강자 사이에 익명성을 제공하면서 동시에 사용하기 간편한 새로운 형태의 의사 소통 수단을 제공할 수 있다는 것을 보여주고 있다. 설 문 조사와는 직접 연관되지 않은 사전의 수회의 수업 중 퀴즈 성적이 수강생의 핸드폰에 축적되는 과정은 수강생 으로 하여금 해당 수업에 항상 관심을 갖도록 유도하는 효과를 보였으며, 교수자 역시 수강생의 성적변화를 즉각 적으로 관찰할 수 있어 수강생의 학습 상태를 손쉽게 파 악할 수 있었다. 본 프로그램은 수업 중 효과적인 의사소 통을 제공하는 하나의 교육도구이므로 전 대학 차원과 같은 다양한 교수환경에서의 테스트를 통한 효과적인 활 용방법에 대한 추가적인 연구가 요구된다. 
[표 1] 설문 조사 문항

\begin{tabular}{|c|c|}
\hline 번호 & 설문내용 \\
\hline 1 & 본 프로그램은 수업 중 사용하게에 편리하였는가? \\
\hline 2 & $\begin{array}{l}\text { 본 프로그램을 이용한 강의 중에 이루어질 즉각적인닟 } \\
\text { 심험을 대하기 위해서 수업 전반에 대한 집중 및 } \\
\text { 몰도가 향상 되었습니까? }\end{array}$ \\
\hline 3 & 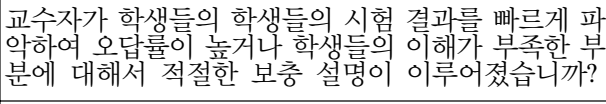 \\
\hline 4 & $\begin{array}{l}\text { 본 프로그램이 강의의 난이도를 조정하는 역할을 할 } \\
\text { 수 있다고 생각하십니까? }\end{array}$ \\
\hline 5 & $\begin{array}{l}\text { 본 프로그램이 강의의 질을 높이는데 기여할 수 있 } \\
\text { 다고 생각하십니까? }\end{array}$ \\
\hline 6 & $\begin{array}{l}\text { 본 프로그램을 강의에 지속적으로 이용하는 것에 긍 } \\
\text { 승각하십니까? }\end{array}$ \\
\hline
\end{tabular}

[표 2] 설문조사결과(단위:\%)

\begin{tabular}{|l|l|l|l|l|l|}
\hline $\begin{array}{c}\text { 문한 } \\
\text { 번호 }\end{array}$ & $\begin{array}{c}\text { 매우 } \\
\text { 그렇다 }\end{array}$ & 그렇다 & $\begin{array}{c}\text { 잘모르 } \\
\text { 겠다 }\end{array}$ & 아니다 & $\begin{array}{c}\text { 매우 } \\
\text { 아니다 }\end{array}$ \\
\hline 1 & 15.79 & 52.63 & 18.42 & 13.16 & 0 \\
\hline 2 & 15.79 & 57.89 & 21.05 & 2.63 & 0 \\
\hline 3 & 13.16 & 57.89 & 21.05 & 5.26 & 0 \\
\hline 4 & 18.42 & 52.63 & 26.31 & 2.63 & 2.63 \\
\hline 5 & 13.16 & 57.89 & 18.42 & 10.53 & 0 \\
\hline 6 & 7.89 & 57.89 & 23.68 & 10.53 & 0 \\
\hline
\end{tabular}

\section{4. 결론}

본 논문에서는 교육현장에서 활용할 수 있는 교수자와 학습자 사이의 효과적인 의사소통의 도구로 $\mathrm{SMS}$ 를 이 용한 모바일 퀴즈 시스템을 제안하여 구현하였다.

현장적용 후 설문조사를 통해, 개발된 시스템이 수업 현장에서 요구되는 익명성, 즉시성, 편리성 및 경제성의 요구사항을 모두 만족시킬 수 있음을 보였다.

본 시스템은 소극적이고 피동적인 학습현장에서 타인 을 의식하지 않아도 되는 익명성을 보장할 수 있는 응답 방법을 제공하여 보다 적극적인 수강생의 응답을 유도하 였으며, 교수자는 즉각적으로 회신되는 수강생의 퀴즈 정 답률 및 수업진행 관련 질문에 대한 응답을 참고로 강의 의 수준과 완급을 효과적으로 조절할 수 있었다. 수강생 의 경우, 학습 내용을 바로 현장에서 평가 받는 형식이므 로 강의에 대한 몰입도가 높아지고, 개인별로 회신되는 퀴즈성적은 학습 현장에서 보다 자발적으로 수업에 참여
하게 하였으며, 지속적으로 자신의 휴대폰에 축적되는 퀴 즈 성적은 해당 수업에 계속적으로 관심이 집중되도록 하였다.

본 논문의 시스템이 제공하는 특징들 중에 익명성이 학습도구로서의 효용을 높이는 제일 요소라고 응답한 결 과는 본 논문의 동기와 부합되며 입시위주의 주입식 교 육이 초래한 문제점이라 볼 수 있으며, 본 논문의 시스템 이 이런 부분을 보완할 수 있는 교육보조도구로 활용될 수 있을 것이다.

본 프로그램은 수업 중 원활하지 않은 의사소통 상황 을 완화시켜줄 수 있는 하나의 교육보조도구로 전 대학 차원과 같은 다양한 교수환경에서의 테스트를 통한 효과 적인 활용방법에 대한 추가적인 연구가 요구된다.

\section{참고문헌}

[1] 나종원, 양정태, "SMS 서비스를 활용한 학습시스템 의 구현" 한국항행학회, 2008. 8

[2] 최강일, "퀴즈와 모바일용 문자메세지를 결합한 양방 향성 모바일용 광고BM", 특허출원, 2002.

[3] 문준기, "SMS를 활용한 교육기관관리 시스템 구축", 중앙대학교 정보대학원 석사학위논문 2006.

[4] 장병철, 장재영, 차재희, "이동형 교육정보 서비스의 개발” 한국컴퓨터교육학회, 2002. 1

[5] 양준혁, 김희진, 한성호, 박원규, "휴대폰 문자 메시 지(SMS) 검색 기능의 사용성 평가" 대한인간공학회 학술대회논문집, 2007.

[6] 이건창, 권순재, "효과적인 강의를 위한 인지적 교수학습모형 개발연구" 경영교육연구 제 10 권 2 호, 2007. 2

[7] 최성호, "효과적인 원격 강의를 위한 콘텐츠 개발의 방향” 한국어린이미디어학회 학술대회자료집, 2005. 5.

[8] 이진희, "e-Learning에서의 커뮤니티 활성화와 학습참 여도에 관한 연구“ 한국컨텐츠학회 춘계종합학술대 회 2006.

[9] 김태훈, 서용무 “효과적인 가상강의를 위한 개선방안 에 관한 연구” 정보기술과 데이터베이스저널 제 8 권 제2호, 2001. 
박 효 원(Hyo-won Park)

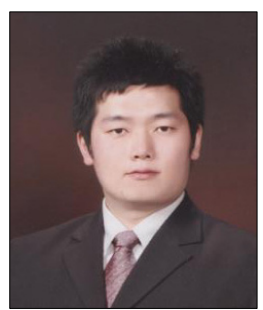

- 2009년 2월 : 순천향대학교 정보 기술공학부 졸업

- 2009년 3월 현재 : 순천향대 학교 정보통신공학과 석사 과정

<관심분야>

서버, 웹, 멀티미디어 컨텐츠 개발, 컴퓨터네트워크, 모바 일 프로그래밍

이 경 득(Kyoung-deug Lee)

[준회원]

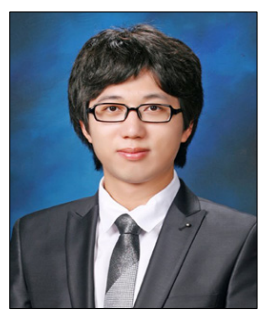

- 2009년 3월 현재 : 순천향대 학교 정보기술공학부 재학중

<관심분야>

윈도우 프로그래밍, 컴퓨터 네트워크, 서버

이 순 흠(Sunheum Lee)

[정회원]

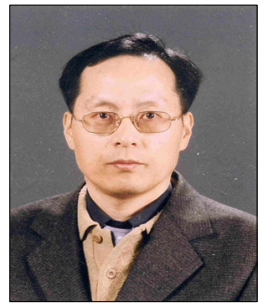

- 1983년 2월 : 고려대학교 전자공 학과(공학사)

- 1985년 2월 : 고려대학교 전자공 학과(공학석사)

- 1989년 8월 : 고려대학교 전자공 학과(공학박사)

- 1991년 9월 현재 : 순천향대 학교 정보통신공학과 교수

<관심분야>

멀티미디어 컨텐츠 개발, 임베디드 시스템, 컴퓨터네트워 크

\section{김 선 형(SunHyung Kim)}

[정회원]
- 1988년 2월 : 성균관대학교 대학 원 전자공학과(공학박사)

- 1989년 3월 현재 : 순천향대 학교 정보통신과 교수

<관심분야>

데이터통신, 교환전송시스템, RFID 